\title{
Assessment of the Impact of Changing Activities' Start Times on Cash-Flow Parameters
}

\author{
Marwa Hussein Ahmed ${ }^{1}$, Tarek Zayed ${ }^{2 *}$ and Ashraf Elazouni ${ }^{3}$ \\ ${ }^{1}$ PhD candidate, Dept of Building, Civil, and Environmental Engineering, Concordia University, Canada \\ ${ }^{2}$ Professor, Dept of Building and Real Estate (BRE), the Hong Kong Polytechnic University, Hung Hom, Kowloon, Hong Kong \\ ${ }^{3}$ Department of Civil and Architectural Engineering College of Engineering, Sultan Qaboos University. P.O. Box 33, Al khoud 123 Muscat, Oman \\ Received: September 26, 2018; Accepted: October 16, 2018; Published: October 31, 2018 \\ *Corresponding author: Tarek Zayed, Professor, Department of Building and Real Estate (BRE), The Hong Kong Polytechnic University, Hung \\ Hom, Kowloon, Hong Kong, Email: tarek.zayed@polyu.edu.hk
}

\begin{abstract}
Contractors usually manage multiple activities within a single project in which activities' start times are controlling the values of cash-flow parameters. Since, in any given schedule, the start time of activities vary while their dependencies are maintained, the other cash-flow parameters vary. Therefore, Simulation technique has been employed to generate schedules and their associated cash flow parameters by randomly specifying the activities' start times between their respective early and late start times. Uniform discrete probability distributions are assumed for the activities' start times. In addition, the simulation model considered the stochastic nature of cash in and cash out transactions in the cash flow model considering the impact of 43 qualitative factors. Three scenarios are defined; each incorporating a different number of qualitative factors which impact the project cash inflow and cash outflow transactions. Advanced sensitivity analysis is performed to measure the impact of changing the start times on cash flow. The activities' criticality to cash-flow parameters is assessed by evaluating the number of times a given activity determined a particular cash-flow parameter over the number of runs. This criticality measurement offers project managers useful criteria with which to identify the activities that are most urgent to be completed on time.
\end{abstract}

Keywords: Cash flow forecasting mode; Activities' criticality; CPM; Simulation;

\section{Introduction}

Construction projects are composed of specific activities, and it is the activities' start times that are the inherent variables which determine the cash inflow and cash outflow transactions of a project's cash flow. The cash inflow and outflow transactions in turn determine the other cash flow parameters including the negative cumulative balance, which constitutes the contractor's cumulative debt, financing cost, and profit for each project. Cash flow forecasts should incorporate the impact of the stochastic variables that influence the cash inflow and outflow transactions. This incorporation of the impact of the stochastic variables improves the accuracy of forecasting the cash flow parameters, which makes contractors more prepared to deal with real encounters. Non-realistic cash flow forecasting is the main cause of financial failure for contractors (and for other businesses as well) (Navon R, [14]).

Cash-flow parameters, including the maximum value of the cumulative negative balance, financing cost, project profit and project duration, vary according to the specified values of the stochastic activities' start times. In this paper, the CPM networks are linked to the cash-flow models such that the delays in the activities start times are reflected directly in the calculation of the cash-flow parameters. Discrete uniform probability distributions can reasonably be assumed to sample start times within the ranges between activities' early and late start times. Discrete uniform distributions assign equal probability to the start times within the specified range.

The Monte Carlo simulation technique is used to generate schedules by sampling from the discrete uniform distributions of the activities start times while maintaining activities' relationships and calculates the associated cash flow parameters.

Accordingly, the activities' criticality can reliably be assessed using the correlation and quantitatively evaluated using the correlation coefficient. Likewise, the activities' criticality related to the cash flow parameters describes the sensitivity of the individual cash-flow parameters to the delays in their start times. Currently, there is a lack of a tool in the literature that practitioners can use to assess an activity's criticality to cash flow parameters.

\section{Research Objectives}

The main objective of this research is to establish a methodology and develop a model to assess the impact of stochastic activities' start times on cash flow parameters, in particular, the uncertainty of cash inflow and outflow.

\section{Background}

\section{Cash Flow Forecasting Models}

Generating an automated cash flow forecast at the project level is a very important and difficult task. In order to ensure the 
accuracy of cash flow forecasting models, the cost and earned value estimates have to be as accurate as possible (Navon, [14]; Park, et al. [17]). The S curve theory has been adopted as the basis for cash flow prediction and is used as the foundation of forecasting. The cost flow curve can be simulated accurately if all of the monthly cost values are available. The cost values are used to fit the S curve, a process which can be used to update all the monthly cost values for a project contract (Hwee and Tiong, [8]; Kaka and Lewis, [10]).

Cash flow forecasting models should be developed before submitting tenders, as a means to preview the distribution of cash flow and the amount of equity required. Cash flow forecasting models are used to preview fund-related requirements and they can be used to manage the fluctuation of the project cash balance. (Cheng C, et al. [3])

Many researchers have studied cash flow forecasting. Au and Hendrickson (1986) developed a cash flow forecasting model. Their model determines the cumulative cash flow at the end of a set period, the net balance (defined as net cash flow at the end of a set period and after receiving a payment), the total financing cost, the accumulated financing cost, the cumulative negative balance at end of a period and the net cumulative cash flow or the project's profit. Navon, [14] developed a cash flow management model for the organizational level, using a detailed computer program which can be used at both the company and the project level to compute the expected capital cost and determine the loans needed. Navon's model incorporates a time lag, so it is considered to be a tool for forecasting cash flow, thanks to its flexibility. However, this model does not consider the uncertainty environment

Hwee and Tiong, [8] developed a model that has a cash flow forecasting ability. The model uses a program to predict the trend of cash flows in a project, and accounts for a degree of uncertainty. The Internal Rate of Return (IRR) is presented as the performance of the project's profit, due to the lost cost of interest. Kaka and Lewis, [10] presented a dynamic cash flow forecasting model that would assist contractors to effectively plan and manage the cash flow of individual projects at a company level. Park, et al [17] proposed a model to forecast cash flow during construction based on the planned earned value. This study introduced moving weights of cost categories, dependent upon the progress of a project. Their model can be used as a simple tool to forecast cash flow at the jobsite; however, it has some shortcomings as it depends on managing the cost and earned value each month, and it ignores the inherent difficulties involved in obtaining reliable variables at the jobsite. Elazouni A, [5] developed mathematical equations to calculate cash flow parameters from the contractors' perspective as Contractors normally deposit the payments into the credit-line accounts to continually reduce the outstanding debit (cumulative negative balance). Other Contractors use loans to borrow money and reduce the negative cash flow (Alavipour and Arditi, 2018). Cheng, et al. [3] developed a cash flow forecasting model. Their model uses the average values of construction scheduling predictions to decrease variation, reduce costs and increase earnings, but this use of averaged figures can be considered one of its shortcomings. Zayed and Liu, [20] developed a cash flow mathematical model that considers uncertainty. Their model can be used as an automated tool to forecast cash flow.

\section{Factors Affecting Project Cash Flow}

Many factors that affect project cash flow have been identified in the literature. Cash flow forecasting models need to incorporate the factors that affect cash inflow and cash outflow to achieve a reasonable accuracy with their project cash flow forecast (Hwee and Tiong, [8]; Chen, et al. [4]; Kaka and Lewis, [17]; Zayed and Liu, [20]). Hwee and Tiong, [8] studied the impact of five factors that impact project cash flow: project duration, over- and under estimation of risk measurement, risk variation and material cost. Chen, et al. [4] considered three factors that affect cost flow forecasting, time lag, frequency, and payment component. Kaka and Lewis, [17] studied 20 variables that affect cash flow. These variables were divided into characteristic variables and classification variables. AlIssa and Zayed, [2] identified 43 factors that affect project cash flow in highway construction project. These factors are divided into seven groups: Financial management, Subcontractors, Suppliers, Prior to construction, during construction, Communication skills, and other factors. The impacts of these factors are utilized in this research and are listed as indicated in Table 1. Zayed and Liu, [20] quantified the impact of the 43 factors that affect highway construction projects.

\section{Scheduling Problems with Cash Flow}

Faced with high interest rates and high costs, the maximization of a project's present value is the objective of project scheduling, in addition to minimizing project duration. The early scheduling of activities with high positive cash flows combined with delaying activities with high negative cash flow can increase net present value (Russell, [18]; Zhu and Padman, [21]; Waligora, [7]). Scheduling activities should be done so that cash inflow occurs early and cash outflow occurs later. (Padman and Zhu, [16]; Kimms, [11]; Vanhoucke, et al. [19]). The Resource Investment Problem (RIP) is defined as the problem of minimizing renewable resource costs subject to a project due date. The objective is to obtain a schedule aligned with the resource requirements (Najafi and Azimi, [13]).

The cost-schedule integration technique assumes that cash flows for a project are a function of the project schedule makes extensive use of the project estimate and schedule data. The integration between scheduling and cash flow requires detailed information such as the bill(s) of quantities and detailed schedules, including activity descriptions and activity durations with all the resources needed for these activities (Chen, et al, [4]; Navon, [14]).

Many researchers have focused on the domain of ResourceConstrained Scheduling Problems (RCSP) with cash flow. Zhu and Padman, [21] applied tabu search Meta heuristics procedures to produce the best schedules in over $85 \%$ of the projects. Waligora, [7] elaborates the properties of an optimal schedule and formulates a mathematical programming problem for 
optimal resource allocation. Padman and Zhu, [16] presented a problem space computational model to solve the scheduling problem with cash flow. Najafi and Azimi, [13] defined the project scheduling problem as the combination of precedence constraints and resource constraints, such as project duration, project total cost and optimization of net present value. Navon, [14] developed automatic cost/schedule integration, which allows the cost of each resource to associate automatically with its appropriate activity. Chen, et al. [4] presented a methodology to assess the accuracy of Cost Schedule Integration (CSI) models and their components. Chen and Weng, (2009) proposed GA model that considered the problems of time cost trade off and resource constrains scheduling problems. The main purpose of their model is to generate schedules. Maravas and pantouvakis (2012) developed a method for project managers to incorporate the source of uncertainty. Their developed method can assist managers with working capital requirements; it can be used for earned value. However, authors did not incorporate factors impacting cash in and out flow. Han, et al. (2014) proposed a method to predict project profit, evaluate projects and determine the negative balance. The authors examined risk variables and its impact on project cost. However, the example application did not describe the cost increase at the activity level. A detailed schedule is recommended for a better forecasting of project cash flow. Han, et al. (2014) recommended the future work, they advised that different factors should be defined and incorporated with the cash flow to address the cost increase. Lu, et al. (2016) developed a methodology frame work to analyze cash flow and support decision making. The framework helped contractors to accurately define alternatives. However, the proposed framework did not consider uncertainty. It neglected sub contractor's factor cost. El-Abbasy, et al. (2017) proposed multi objective scheduling optimization model for multiple construction projects. The model included project scheduling, resource allocation and cash flow forecasting. Alavipour and Arditi, (2018) developed a model to minimize financing, the model generated cash flow based on a CPM network.

\section{Monte Carlo Simulation}

Many researchers have used the Monte Carlo simulation technique to solve problems related to cash flow. Ölveczky and Caccamo, [15] focused on a cash algorithm to maximize system performance, while guaranteeing that critical tasks are executed in a timely manner. Javid and Seneviratne, [9] constructed a financial model to evaluate net present value using Monte Carlo simulation to evaluate the impact of alternative financing structures. They used Monte Carlo simulation to estimate the impact of cash flow uncertainties on project feasibility. The authors defined investment risk as the probability of the net present value (N.P.V) to be less than the target value. Kaka and Lewis, [10] developed a dynamic cash flow forecasting model to help contractors to plan and manage the cash flow of individual projects at a company level. The model took into account many variables because it considered the uncertainty. Zayed and Liu, [20] considered the factors that affect highway construction project cash flow and the impact of these factors on the cash flow as random variables. A cash flow model was established by integrating the Analytic Hierarchy Process (AHP) and a Monte Carlo simulation to examine the impact of various factors on cash flow.

\section{Literature Gap}

According to the literature review, the existing models in the different areas such as cash flow forecasting have some shortcomings, one of which is that the majority of the scheduling schemes with cash flow problems neglect the financing cost as a project cost component. Moreover, none of the studies evaluated the impact and criticality of activities to the cash-flow parameters by stochastically assigning different start times while considering the uncertainty of the cash outflow and inflow transactions. This research focuses on this gap with the goal of allowing contractors to assess the impact of delaying activities' start times on cash flow parameters, including the financing cost, maximum negative cumulative balance, project duration, and project profit. This impact represents a metric with which to assess the activities' criticality related to the cash flow parameters.

\section{Research Methodology}

A system of steps, illustrated in Figure 1, is designed to satisfy our main goal, to determine the impact of activities' start times on cash flow parameters. A Monte Carlo simulation was used to generate random variables for inputs, which are the start times of the activities. The outputs of the model are the cash flow parameters, including the total project duration, financing cost, maximum negative cumulative balance, and project profit. @RISK, a commercially available software package, was used to implement the Monte Carlo simulation. The methodology assesses the criticality of activities to cash flow parameters. It generates alternative schedules that are modeled in the MS Excel environment. The developed Critical Path Method (CPM) model is integrated with a cash flow model to calculate the cash flow parameters. In addition, the impacts of various qualitative factors are taken into consideration. A sensitivity analysis was carried out to assess the criticality of various activities to the cash flow parameters. Figure 1 shows a flow chart of the main sections and subsections of the model development.

\section{Cash Flow Model Development}

A sample project is used to illustrate the proposed methodology. This project consists of 15 activities with the durations indicated in working days. The overhead costs of the project were considered to be $15 \%$ of the direct cost, and the cash inflow calculations resemble a typical cost plus fee contract with a $20 \%$ fee percentage. A 5 -day week period was used for this project. The payments were made 2 weeks after submission of the weekly pay requests, with no advance payment.

The CPM model, which is built in an Excel environment, takes the activity data as inputs and calculates the early start, early finish, late start, late finish and the total float of the activities based on the activities' durations and on the dependencies between activities. Activities C, F, G, J, M and O exhibited total float values of zero and thus were considered the critical activities. Figure 2 


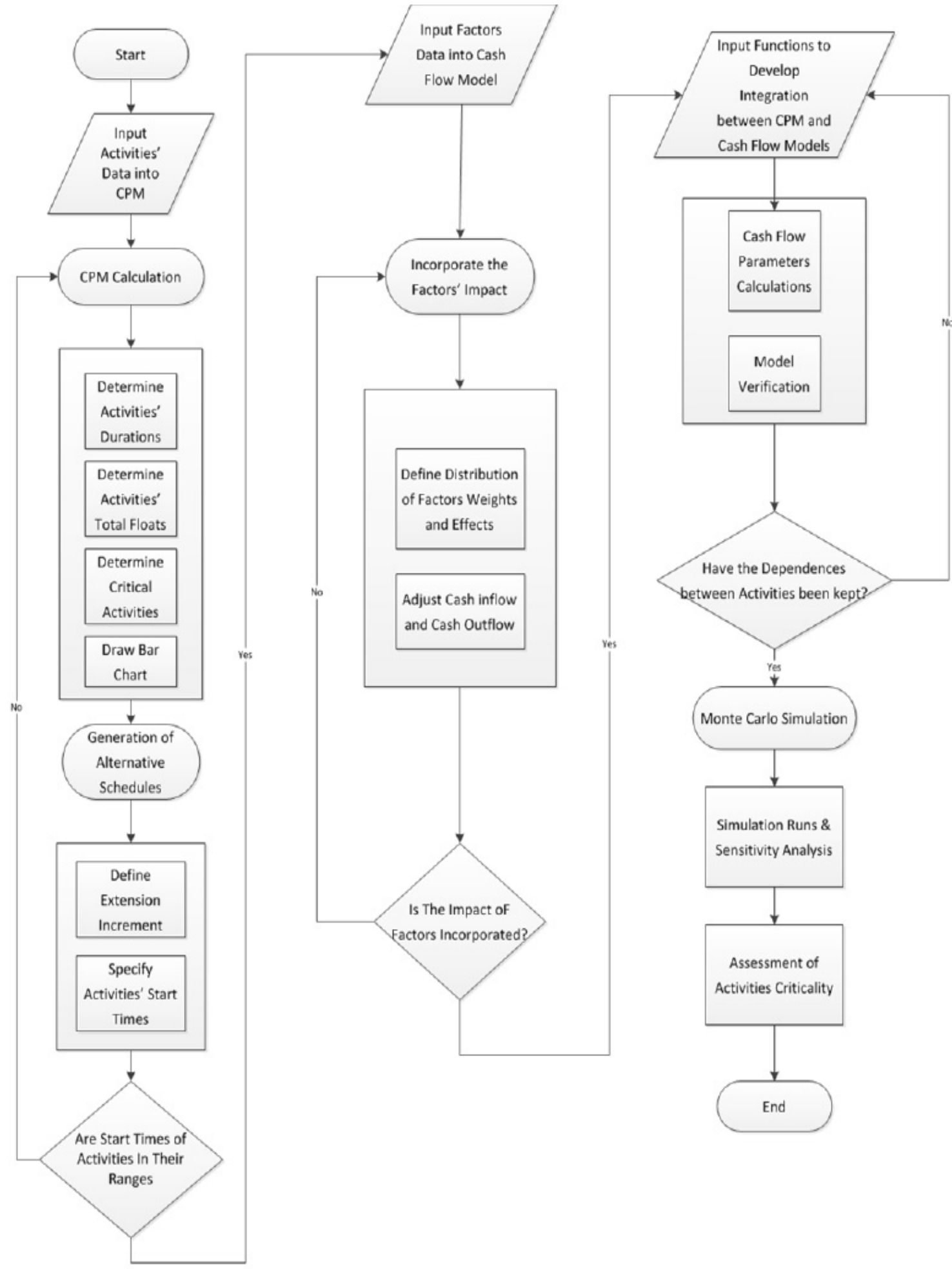

Figure 1: The model development 


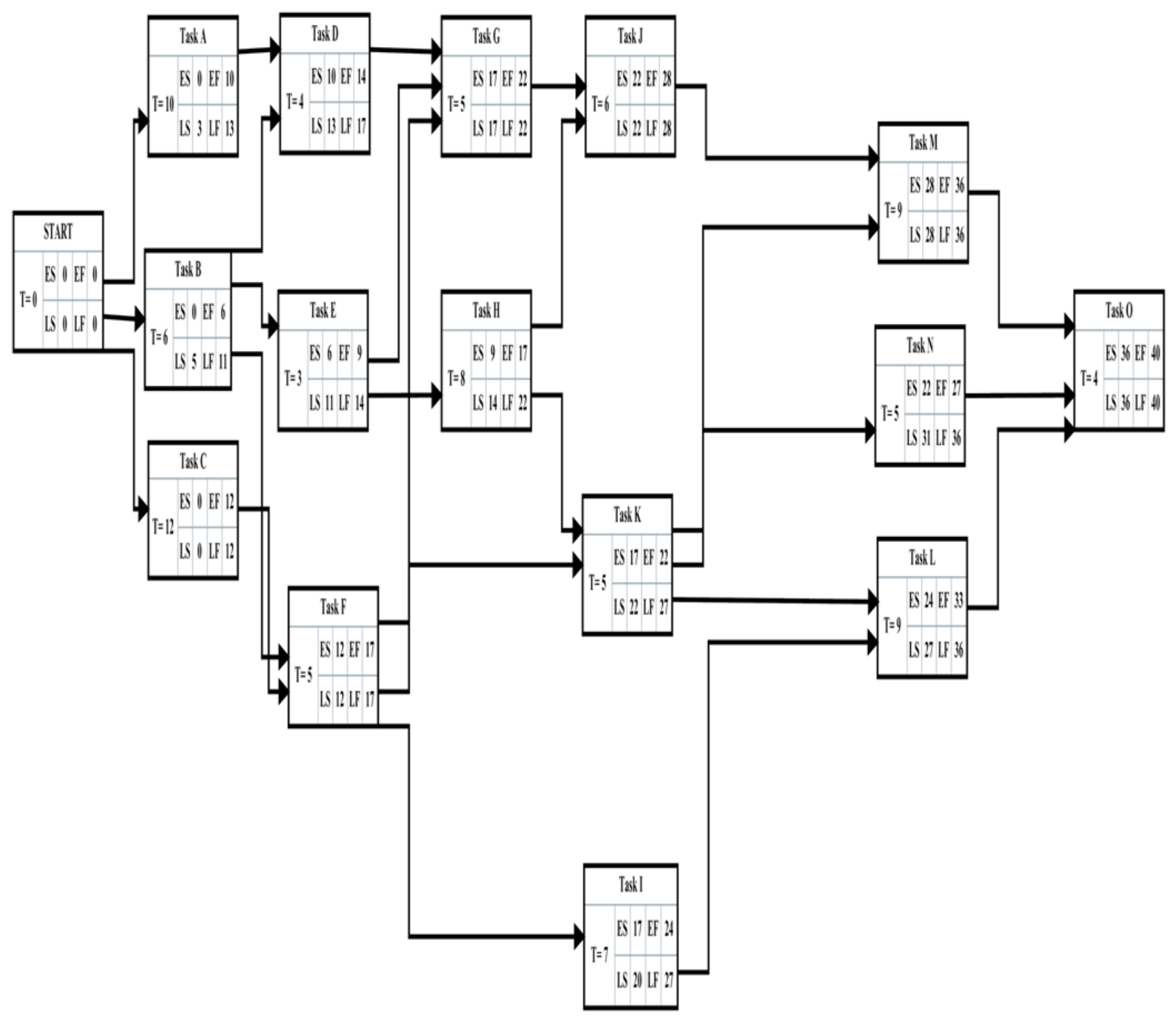

Figure 2: Activities network

shows the CPM network of the project activities' durations with all the CPM calculations. The start times of activities are defined in specific ranges. These specific ranges are determined based on the extension scheme. Different schedules are generated by assigning different activity start times, within their respective ranges. The start time of each activity can be shifted within a range defined by an early to a late start, plus an extension increment, while maintaining the dependencies between activities.

This range has been assumed to have a discrete uniform probability distribution such that all the values will have the same probability to occur. Discrete random variables are used to describe random phenomena in which the random variables can take only the integer values. The start times of the activities have been defined using the @RISK software, which employs the Monte Carlo simulation. Upon running the model for 500 iterations, the @RISK application generates 500 alternative schedules. The Monte Carlo simulation takes a random activity start time value of the specified range and then the Excel model performs the other CPM calculations.

The total direct cost of each day was calculated as the sum of the direct costs of all the activities ongoing that day. The total direct cost of each week was calculated as the sum of the total direct cost of the five days comprising that week. Cash outflow is the total direct cost of each week plus the overhead. Cash inflow is the cash outflow of each week plus the mark up. To stochastically incorporate the impact of the quantitative factors on the cash inflow and outflow transactions, the probability distribution of the weight and the effect of each factor defined by Zayed and 
Liu, [20] were used. The cash outflow of each week is calculated based on the total direct cost plus the overhead, incorporating the combined impact of all the weights and effects of all the cash outflow qualitative factors. The cash inflow is calculated as the cash outflow plus the mark up, thereby incorporating the impact of all the qualitative factors that affect the cash inflow. Equations 1 and 2, developed by Zayed and Liu, [20], are used to adjust cash inflow and outflow in order to incorporate the impact of the factors that affect the cash inflow and cash outflow transactions, using stochastic analysis.

\section{Cash inflow model $=\left(1-\sum_{l=1}^{n} \boldsymbol{W}_{l} * \boldsymbol{E}_{l} * \boldsymbol{P}\right) *$ Cash in $_{\boldsymbol{m}}$ Eq. 1}

Where $W_{l}$ is the weight of factor $\mathrm{l} ; E_{l}$ is the effect of factor $\mathrm{l}$; P is the percent of cash that represents the factors' effect, and $C_{i n-m}$ is the owner payment at specific time period m.
Cash outflow $=\left(1+\sum_{k=1}^{n} \boldsymbol{W}_{\boldsymbol{k}} * \boldsymbol{E}_{\boldsymbol{k}} * \boldsymbol{P}\right) *(1+\boldsymbol{i}) *$ Cash out $\boldsymbol{m}_{\boldsymbol{m}}$ Eq. 2

Where $W_{k}$ is the weight of factor $\mathrm{k}$, and $E_{k}$ is the effect of factor k. $C_{\text {out }-m}$ is the estimated cash outflow of the project at a specific time $\mathrm{m} . \mathrm{P}$ is the range of percentage of cash that is affected by the qualitative factors; it represents the cash involved in the calculations. In order to get the accurate value of the p percent, which is the percentage of cash that is affected by the qualitative factors' effect a special questionnaire was designed as part of the current study and sent to thirty companies in North America. Companies are selected based on their experience and based on data availability of their contact information. Eleven companies responded which constitutes $37 \%$ of the total distributed. The results showed that $\mathrm{P}$ percent follow a triangle probability distribution, with a minimum value of $4 \%$, a maximum value of $60 \%$, and a mean value of $35 \%$. Table 2 shows that the impact of the qualitative factors that affect the cash inflow decreases the cash inflow by $9 \%$. In Table 3 , the impact of the factors that affect the cash outflow is calculated to be $10.6 \%$, which means that the cash outflow transactions will be increased by this percent.

\begin{tabular}{|c|c|c|}
\hline Category & \multicolumn{2}{|c|}{ Factors } \\
\hline $\begin{array}{c}\text { Financial } \\
\text { Management }\end{array}$ & $\begin{array}{l}\text { F1-Change of progress payment duration (I) } \\
\text { F2-Change of progress payment conditions (I) } \\
\text { F3- Receiving front payment (I) } \\
\text { F4-Large retention percent (I) } \\
\text { F5-Delay in releasing retention (I) } \\
\text { F6-Finanical position (O) }\end{array}$ & $\begin{array}{c}\text { F7-Loan repayment }(0) \\
\text { F8-Payments of material (before/after arrival) (0) } \\
\text { F9-Over work measurement (I\&0) } \\
\text { F10-Under work measurement }(\mathrm{I \& O}) \\
\text { F11-Change of labor and staff wages }(0) \\
\text { F12-Bank interest }(0)\end{array}$ \\
\hline Sub-contractor & $\begin{array}{l}\text { Sub1-Decisions to sub-contract }(0) \\
\text { Sub2-Over/under measurement }(0)\end{array}$ & $\begin{array}{l}\text { Sub3-Failure of sub-contractor (I\&0) } \\
\text { Sub4-Renting vs. buying equipment (0) }\end{array}$ \\
\hline Suppliers & $\begin{array}{l}\text { Sup1-Delay of making payments (0) } \\
\text { Sup2-Procurement problems (0) }\end{array}$ & $\begin{array}{l}\text { Sup3-Delay in delivery }(I \& 0) \\
\text { Sup4-Price change }(0)\end{array}$ \\
\hline \multirow{2}{*}{$\begin{array}{c}\text { Prior to } \\
\text { Construction }\end{array}$} & $\begin{array}{c}\text { P1-Poor design (0) } \\
\text { P2-Inaccurate bid items (I\&0) }\end{array}$ & $\begin{array}{l}\text { P4-Cash flow forecasting }(0) \\
\text { P5-Competitors (I) }\end{array}$ \\
\hline & P3-Estimating strategies (0) & \\
\hline $\begin{array}{c}\text { During } \\
\text { Construction }\end{array}$ & $\begin{array}{l}\text { D1-Mistakes in executing the work (I\&O) } \\
\text { D2-Lack of adequate insurance (O) } \\
\text { D3-Replacement of defective work (I\&O) } \\
\text { D4-Large project's duration increase/decrease (I\&O) }\end{array}$ & $\begin{array}{c}\text { D5-Small project's duration increase/decrease (I\&O) } \\
\text { D6-Project delayed (I\&O) } \\
\text { D7-Material and equipment shortages (O) } \\
\text { D8-Lack of skilled labor (O) } \\
\text { D9-Improper planning and management (I\&O) }\end{array}$ \\
\hline $\begin{array}{l}\text { Communication } \\
\text { Skills }\end{array}$ & $\begin{array}{l}\text { C1-Disputes between contractor and owner (I\&O) } \\
\text { C2-Poor communication -contractor staff (I\&O) }\end{array}$ & $\begin{array}{l}\text { C3-Relations with owner (I\&O) } \\
\text { C4-Relations with consultant team (0) }\end{array}$ \\
\hline Others & $\begin{array}{l}\text { 01-Weather condition (I\&0) } \\
\text { 02-Positive change order (addition work) (I\&0) }\end{array}$ & $\begin{array}{c}\text { O3 -Negative change order (I\&O) } \\
\text { O4-Inability to manage change orders (I\&O) } \\
\text { O5-Number of claims (I\&O) }\end{array}$ \\
\hline
\end{tabular}

Note: (I): affects cash-in; (O): affects cash-out; (I\&O): affects cash-in and cash-out 
Table 2: Application of the adjustment model of the cash inflow

\begin{tabular}{|c|c|c|c|c|}
\hline Factors & $\begin{array}{c}\text { Weight } \\
\text { (W) }\end{array}$ & Effect (E) & $\mathbf{P}$ & $\mathbf{W}^{*} \mathbf{E}^{*} \mathbf{P}$ \\
\hline F1 & 0.02617 & 0.819 & 0.3 & 0.00643 \\
\hline F2 & 0.018995 & 0.713 & 0.3 & 0.004063 \\
\hline F3 & 0.019968 & 0.758 & 0.3 & 0.004541 \\
\hline F4 & 0.018021 & 0.704 & 0.3 & 0.003806 \\
\hline F5 & 0.013871 & 0.626 & 0.3 & 0.002605 \\
\hline F9 & 0.015617 & 0.666 & 0.3 & 0.00312 \\
\hline F10 & 0.014745 & 0.664 & 0.3 & 0.002937 \\
\hline P2 & 0.011678 & 0.572 & 0.3 & 0.002004 \\
\hline P5 & 0.011448 & 0.613 & 0.3 & 0.002105 \\
\hline D1 & 0.017889 & 0.708 & 0.3 & 0.0038 \\
\hline D3 & 0.01139 & 0.525 & 0.3 & 0.001794 \\
\hline D4 & 0.018397 & 0.715 & 0.3 & 0.003946 \\
\hline D5 & 0.012533 & 0.635 & 0.3 & 0.002388 \\
\hline D6 & 0.022081 & 0.813 & 0.3 & 0.005386 \\
\hline D9 & 0.02268 & 0.856 & 0.3 & 0.005824 \\
\hline C1 & 0.016145 & 0.689 & 0.3 & 0.003337 \\
\hline $\mathrm{C} 2$ & 0.013209 & 0.645 & 0.3 & 0.002556 \\
\hline $\mathrm{C} 3$ & 0.015893 & 0.738 & 0.3 & 0.003519 \\
\hline Sub3 & 0.019504 & 0.695 & 0.3 & 0.004067 \\
\hline Sup3 & 0.017976 & 0.719 & 0.3 & 0.003877 \\
\hline 01 & 0.01765 & 0.633 & 0.3 & 0.003352 \\
\hline 02 & 0.017296 & 0.61 & 0.3 & 0.003165 \\
\hline 03 & 0.010495 & 0.511 & 0.3 & 0.001609 \\
\hline 04 & 0.02141 & 0.719 & 0.3 & 0.004618 \\
\hline 05 & 0.020461 & 0.686 & 0.3 & 0.004211 \\
\hline \multicolumn{4}{|c|}{ 1- Sum $\mathbf{W}^{*} \mathbf{E}^{*} \mathbf{P}=$} & 0.910941 \\
\hline
\end{tabular}

\section{Integration of CPM and Cash Flow Model}

The integration of CPM and cash flow model is established in order to study the impact of the stochastic start times of activities on the cash flow parameters' value calculations. This integration was implemented based on the activities' daily direct costs, which are assumed to be associated throughout the activities' durations from their start times to their finish times. To represent the activities' daily direct costs along with their durations, the integration used functions for all of the activities' durations throughout the total project duration. To illustrate these functions, an example of the equation used for the first day of direct cost representation for activity A is shown here in equation 3 .
Table 3: Application of the Adjustment Model of the Cash Outflow

\begin{tabular}{|c|c|c|c|c|}
\hline Factors & $\begin{array}{l}\text { Weight } \\
\text { (W) }\end{array}$ & Effect(E) & $\mathbf{P}$ & $\mathbf{W}^{*} \mathbf{E}^{*} \mathbf{P}$ \\
\hline F6 & 0.02192 & 0.796 & 0.3 & 0.005234 \\
\hline F7 & 0.01648 & 0.659 & 0.3 & 0.003258 \\
\hline F8 & 0.018614 & 0.729 & 0.3 & 0.004071 \\
\hline F9 & 0.015617 & 0.666 & 0.3 & 0.00312 \\
\hline F10 & 0.014745 & 0.664 & 0.3 & 0.002937 \\
\hline F11 & 0.011054 & 0.605 & 0.3 & 0.002006 \\
\hline F12 & 0.01094 & 0.611 & 0.3 & 0.002005 \\
\hline P1 & 0.019067 & 0.734 & 0.3 & 0.004199 \\
\hline P2 & 0.011678 & 0.572 & 0.3 & 0.002004 \\
\hline P3 & 0.014461 & 0.658 & 0.3 & 0.002855 \\
\hline P4 & 0.019148 & 0.747 & 0.3 & 0.004291 \\
\hline D1 & 0.017889 & 0.708 & 0.3 & 0.0038 \\
\hline D2 & 0.009527 & 0.532 & 0.3 & 0.001521 \\
\hline D3 & 0.01139 & 0.525 & 0.3 & 0.001794 \\
\hline D4 & 0.018397 & 0.715 & 0.3 & 0.003946 \\
\hline D5 & 0.012533 & 0.635 & 0.3 & 0.002388 \\
\hline D6 & 0.022081 & 0.813 & 0.3 & 0.005386 \\
\hline D7 & 0.017897 & 0.739 & 0.3 & 0.003968 \\
\hline D8 & 0.005282 & 0.652 & 0.3 & 0.001033 \\
\hline D9 & 0.02268 & 0.856 & 0.3 & 0.005824 \\
\hline C1 & 0.016145 & 0.689 & 0.3 & 0.003337 \\
\hline C2 & 0.013209 & 0.645 & 0.3 & 0.002556 \\
\hline C3 & 0.015893 & 0.738 & 0.3 & 0.003519 \\
\hline C4 & 0.00896 & 0.554 & 0.3 & 0.001489 \\
\hline Sub1 & 0.014268 & 0.624 & 0.3 & 0.002671 \\
\hline Sub2 & 0.012922 & 0.658 & 0.3 & 0.002551 \\
\hline Sub3 & 0.019504 & 0.695 & 0.3 & 0.004067 \\
\hline Sub4 & 0.013296 & 0.582 & 0.3 & 0.002321 \\
\hline Sup1 & 0.016153 & 0.652 & 0.3 & 0.00316 \\
\hline Sup2 & 0.014114 & 0.627 & 0.3 & 0.002655 \\
\hline Sup3 & 0.017976 & 0.719 & 0.3 & 0.003877 \\
\hline Sup4 & 0.01203 & 0.555 & 0.3 & 0.002003 \\
\hline 01 & 0.01765 & 0.633 & 0.3 & 0.003352 \\
\hline 02 & 0.017296 & 0.61 & 0.3 & 0.003165 \\
\hline \multicolumn{4}{|c|}{$1+\operatorname{Sum} \mathbf{W}^{*} \mathbf{P}^{*} \mathbf{E}$} & 1.106362 \\
\hline
\end{tabular}




$$
f(x)=\left\{\begin{array}{lc}
(x-S A) * \frac{C A}{D A} & \text { If } x>S A \text { and }(x-S A)<1 \text { and } x \leq F A \\
1 * \frac{C A}{D A} & \text { If } x>S A \text { and } x \leq F A \text { and }(x-S A) \geq 1 \\
\left.(F A-F A) * \frac{C A}{D A} \text { If }(x>S A) \& \text { and }(x=F A) \text { and }(x-S A)>1 \text { and }(F A-x)<1\right) \\
0 & \text { otherwise }
\end{array}\right.
$$

Where $\mathrm{x}$ is a deterministic variable that indicates the start time of the activity's direct cost representation. The value of the variable $\mathrm{x}$ can range from one day to the extended total duration. $\mathrm{SA}$ is a stochastic variable; it shows the start time of activity A. FA is a deterministic variable that shows the finish time of activity A. CA is a deterministic variable and indicates the direct cost of activity A. DA is a deterministic variable that gives the duration of activity A. This equation has been defined for each day in the project duration, for each of the project's activities. After the representation of the direct cost of each activity's day, the total direct cost of each day can be calculated.

\section{Cash Flow Parameters}

Elazouni (2009) developed mathematical equations to calculate cash flow parameters from the contractors' perspective as Contractors normally deposit the payments into the credit-line accounts to continually reduce the outstanding debit (cumulative negative balance) The cumulative balance at the end of period $t$ is defined by $F_{t}$ where;

$$
F_{t}=N_{t-1}+E_{t} \text { Eq. } 4
$$

Were, $E_{t}$ is the cash outflow during a typical period t, and $N_{t-1}$ is the cumulative net balance at the end of period t- 1 .

The cumulative net balance at the end of period $t$ after receiving payment $P_{t}$ is defined as $N_{t}$. At the end of period t- 1 , $N_{t-1}$ can be calculated from equation 5 .

$$
N_{t-1}=F_{t-1}+P_{t-1} \text { Eq. } \mathbf{5}
$$

Where $F_{t-1}$ is the cumulative balance, $\mathrm{P}_{\mathrm{t}-1}$ is the payment received, and $N_{t-1}$ is the cumulative net balance. When contractors decide to pay the financing costs at the end of the project, the periodical financing costs are compounded by applying equation 6:

$$
\hat{I}_{t}=\sum_{l=1}^{t} I_{l}(1+r)^{t-l} \text { Eq. } 6
$$

Where $\hat{I}_{t}$ is the cumulative financing cost, $\mathrm{r}$ interest rate. Thus, the cumulative balance at the end of period $t$, including accumulated financing costs, is represented by $\hat{F}_{t}$ which is calculated as:

$$
\hat{F}_{t}=F_{t}+\hat{I}_{t} \text { Eq. } 7
$$

The cumulative net balance including the financing cost is thus $\hat{N}_{t}$ :

$$
\hat{N}_{t}=\hat{F}_{t}+P_{t} \text { Eq. } 8
$$

The positive value of $\hat{N}_{t}$ at the end of the last period $\mathrm{L}$ represents the corporate profit.

The calculation of cash flow parameters depends on the activities' cash outflow and inflow. The cash outflow for a week depends on the total direct cost of the activities in that week plus overhead. The cash inflow is the cash outflow plus the markup, as the project contract is for cost plus fees. In this research, a stochastic interest rate is defined by collecting data for the interest rate of the last 10 years and using the best-fit option in @RISK. The interest rate is defined as a triangular probability distribution with a mean value of $0.19 \%$, minimum value of $0.125 \%$ and maximum value of $0.25 \%$. The weekly cash outflow and cash inflow transactions were determined and adjusted to incorporate the impact of the qualitative factors. The weekly cash outflow is calculated based on the total direct cost of the activities plus overhead, multiplied by 1.106 , which represents the impact of the cash outflow qualitative factors. The weekly cash inflow is calculated based on the weekly cash outflow plus markup multiplied by 0.91 , which represents the impact of the cash inflow qualitative factors. Cash inflow and Cash outflow can be calculated using equations 9,10 and 11 .

$$
E_{t}=\sum_{i=1}^{i=n} D_{i} *(1+O H) * \text { Cout } \quad \text { Eq. } 9
$$

where $E_{t}$ is the cash outflow at time period $\mathrm{t}, \mathrm{n}$ is the number of days comprising the time period, $D_{i}$ is the sum of the total direct cost of all the activities ongoing during one unit of the time period t, $\mathrm{OH}$ is the overhead, and Cout factor is stochastic variable, it is the cash outflow factors' impact.

$$
P_{t}=\left[E_{t-2} *(1+\text { markup })\right] * \operatorname{Cin} \text { Eq. } 10
$$


$P_{t}$ is the cash inflow transaction for the disbursements at time period t. $E_{t-2}$ is the cash outflow at time period t-2; Cin factor is the cash inflow factors' impact, it is stochastic variable.

The cash-flow is developed from the contractors' perspective. Contractors often procure funds from banks by establishing credit-line accounts. Cash flow parameters include maximum negative cumulative balance; project profit and financing cost are calculated using equation 1 till equation 5 that were used before in an earlier study by Elazouni, 2009. These equations are illustrated in details in the background section.

\section{Model Verification}

The proposed methodology has been verified to perform well in the random state. This verification was carried out by using models of functions, run on @RISK. These functions were used for all the activities. As an example the activities' start times are defined by using the following equations:

For an extension increment of five days, the start time of activity $\mathrm{A}$ is defined as

$$
f(x)=\mathrm{x} \quad x \in\{0,1,2,3,4,5,6,7,8\} ;
$$

the start time of activity B as

$$
f(x)=\mathrm{x} \quad x \in\{0,1,2,3,4,5,6,7,8,9,10\} ;
$$

the start time of activity $\mathrm{C}$ as

$$
f(x)=\mathrm{x} \quad x \in\{0,1,2,3,4,5\} ;
$$

And the start time of activity $\mathrm{D}$ as

$$
f(x)=\left\{\begin{array}{ll}
F A, & \text { if } F A>F B \\
F B & \text { otherwise }
\end{array} \quad x \in\{10,11,12,13,14,15,16,17,18\}\right.
$$

Eq. 14

Where FA and FB are deterministic variables that represent the finish times of activities A and B, respectively. The start time of activity $E$ is defined as

$$
f(x)=F B \quad x \in\{6,7,8,9,10,11,12,13,14,15,16\} \quad \text { Eq. } 15
$$

Where FB is a deterministic variable it represents the finish time of activity $\mathrm{B}$.

The start time of activity $\mathrm{F}$ is defined as

$$
f(x)=\left\{\begin{array}{rr}
F B & \text { if } F B>F C \\
F C & \text { otherwise }
\end{array} \quad x \in\{12,13,14,15,16,17\} \quad \text { Eq. } 16\right.
$$

Where $\mathrm{FB}$ and $\mathrm{FC}$ are deterministic variables that represent the finish times of activities $\mathrm{B}$ and $\mathrm{C}$, respectively.

The start time of activity $\mathrm{G}$ is defined as

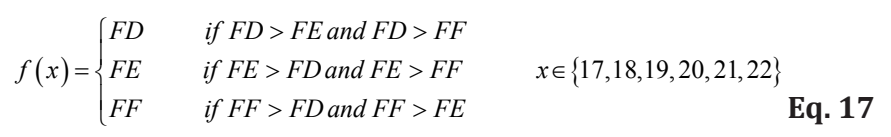

Where FD, FE and FF are deterministic variables representing the finish times of activities D, E and F, respectively.

The advantage of using these models is that they allow the dependencies between the activities to be maintained while applying the Monte Carlo simulation. This is achieved by running the simulation through a number of iterations, suddenly stopping the simulation and saving the resulted new schedules. This procedure was repeated approximately ten times for each extension increment. We thus saved several different schedules which could then be easily checked for the dependencies between activities. Moreover, this procedure ensures that the activities' start times are within the range of the early start time to the late start time plus the extension increment. The direct cost of each activity was verified and calculated for each generated schedule based on the new start and finish times of the activities. The cash outflows and inflows were checked as well, as were the calculations of the other cash flow parameters: the financing cost, the maximum negative cumulative balance and the project profit.

\section{Criticality Assessment Using Monte Carlo Simulation}

For each simulation run, the Monte Carlo simulation specifies the start times of activities in the CPM model. The simulation incorporates uncertainty; it defines the weights and the effects of the factors that affect the cash outflow and inflow in the cash flow model. Upon completing the specified number of runs, the probability distributions of the project duration and the cash flow parameters are obtained. Sensitivity analysis is carried out in order to rank the activities based on their impact on the project duration and on the cash flow parameters. Upon running the simulation iteratively, the results are recorded and displayed in graphs that show the ranges of the cash flow parameters. The probability distributions of the cash flow parameters can also be displayed in a cumulative form.. The activities that have the highest impact on the outputs, the total project duration, the financing cost, the project profit and the maximum negative cumulative balance, are identified as the critical activities. The criticality assessment is carried out with two different analytical techniques: Regression analysis and Correlation calculation.

\section{Scenarios of Case Examples}

In order to consider the stochastic nature of the periodic cash in and cash out transactions in the cash flow model, their values were adjusted to account for the impact of 43 qualitative factors identified in an earlier study. Two scenarios were defined based on the qualitative factors that they incorporate; there is no specific logic to incorporate the factors at each scenario. Scenarios are assumed as three scenarios. Many scenarios can be considered as well. Scenario I incorporates six factors impacting cash inflow transaction: F1- change of progress payment duration; D4- large project duration increase/decrease; D5 small project duration increase/decrease; D6 - project delayed; D9 - improper planning and management; and 01 - weather condition. Scenario II also incorporates nine factors that impact cash outflow transaction: F6 - financial position; F8 - payment of material before/after; F12 - bank interest; P4 - price change; D4 - large project duration increase/decrease; D5 - small project 
duration increase/decrease; D6 - project delayed; D9 - improper planning and management; and 01 - weather condition. Scenario III incorporates all the qualitative factors that impact cash inflow and cash outflow transactions. The qualitative factors increase cash outflow transactions and decrease cash inflow transactions. In this project, cash inflow calculations resemble a typical costplus fee contract. However, in other types of contracts, scenarios II and III could be considered as the most likely case and the worst case, respectively. Upon running the simulation iterations for each scenario, the output results are presented to investigate the variation of the cash flow parameters values with the variation of the start times and the extension increments. The cash flow parameters for the two scenarios are analyzed.

\section{Simulation Results}

Upon running the simulation 500 runs, we can summarize the output results the from two scenarios, considering three extension increments for each scenario. Table 4, Table 5 shows the minimum, the maximum and the mean values of the cash flow parameters for the two scenarios. As presented in Table 4 it is clear that the mean value of the financing cost decreases with the increase of the extension. The results indicate that the mean values of the financing cost for $0,5,10$, and 15-day extension increments are \$404.71, \$397.25, \$390.58 and \$384.47, respectively. With the increase of the duration, the number of the activities ongoing during any period decreases. Accordingly, the contractors' periodical cash out and negative cumulative balance decreases and consequently the financing cost decreases.

The results in Table 4 indicate that the mean value of the maximum cumulative negative balance decreases with the increase of the extension increment. The mean values of the maximum cumulative negative balance for $0,5,10$ and 15-day extension increments are \$46,298.09, \$44,586.89, \$42,893.05 and $\$ 41,377.81$, respectively. Whenever the duration is increased, the number of activities that are ongoing during any period decreases. Accordingly, the amount of cash that a contractor borrows during any period decreases and consequently the maximum negative cumulative balance decreases.

The results in Table 4 indicate that the project profit increases with the increase of the extension increment. The mean values of the profit for the $0,5,10$ and 15-day extension increments are $\$ 21,912.93, \$ 21,923.3, \$ 21,930.91$ and $\$ 21,940.38$, respectively. In the current project, which represents a cost plus contract, the profit varies exclusively according to the variations of the financing cost. The lower the financing cost, the higher the profit. Since the financing cost decreases with the increase of the extension increment, the profit increases with the increase of the extension increment. As presented in Table 4 and Table 5 the mean value of the financing cost and the maximum negative cumulative balance decrease with the increase of the extension. Moreover, their values increase from scenario I to scenario II due to the incorporated qualitative factors, which consequently increase the cash out and decrease the cash inflow transactions. The results indicate that the mean value of the financing cost for scenarios I and II are $\$ 397.25$ and $\$ 432.67$, respectively, with an extension increment of 5 days. The results also show that the mean values of the maximum negative cumulative balance for scenarios I and II are $\$ 44,586.9$ and $\$ 47,972.99$, respectively. The project profit increases from scenario I to scenario II; the results indicate the mean profit values for scenarios I and II are $\$ 21,912$ and $\$ 23,224.60$, respectively, for an extension increment of 5 days. It can be observed that the project profit has no fixed trends with the extensions of 5,10 or 15 days for scenario II, due to the stochastic impact of the qualitative factors.

Table 4: The cash flow parameters for scenario I (Most Likely)

\begin{tabular}{|c|c|c|c|c|c|c|}
\hline Scenario & Cash flow Parameters & \multirow{2}{*}{ Ranges } & \multicolumn{4}{|c|}{ Extension Increment } \\
\hline \multirow{11}{*}{ Scenario I } & \multirow{4}{*}{$\begin{array}{c}\hat{I}_{t}(\$) \\
\text { (Financing cost) }\end{array}$} & & 0 days & 5days & 10 days & 15 days \\
\hline & & Minimum & 269.6 & 257.8 & 244.33 & 258.17 \\
\hline & & Maximum & 542.95 & 547.4 & 544.8 & 520.86 \\
\hline & & Mean & 404.71 & 397.25 & 390.58 & 384.47 \\
\hline & \multirow{2}{*}{$\begin{array}{c}\hat{F}_{t}(\$) \\
\text { (Max negative Balance) }\end{array}$} & Maximum & 51414.77 & 56155.39 & 55991.18 & 55809.91 \\
\hline & & Mean & 46298.09 & 44586.89 & 42893.05 & 41377.81 \\
\hline & \multirow{3}{*}{$\frac{\text { D }}{\text { (Final Project Duration) }}$} & Minimum & 40 days & 42 days & 45 days & 48 days \\
\hline & & Maximum & 40 days & 45 days & 50 days & 55 days \\
\hline & & Mean & 40 days & 44 days & 49 days & 54 days \\
\hline & \multirow{2}{*}{$\begin{array}{c}\hat{\mathrm{N}}_{t}(\$) \\
\text { (Net Project Profit) }\end{array}$} & Maximum & 23044.9 & 23563.09 & 24571.32 & 23100.67 \\
\hline & & Mean & 21912.93 & 21923.26 & 21930.91 & 21940.38 \\
\hline
\end{tabular}




\begin{tabular}{|c|c|c|c|c|c|c|}
\hline Scenario & Cash flow Parameters & \multirow{2}{*}{ Ranges } & \multicolumn{4}{|c|}{ Extension Increment } \\
\hline \multirow{13}{*}{ Scenario II } & \multirow{4}{*}{$\begin{array}{c}\hat{I}_{t}(\$) \\
\text { (Financing cost) }\end{array}$} & & 0 days & 5days & 10 days & 15 days \\
\hline & & Minimum & 276 & 285.8 & 284.6 & 278.16 \\
\hline & & Maximum & 628 & 603.1 & 587.3 & 565.57 \\
\hline & & Mean & 440.9 & 432.4 & 425.22 & 418.3 \\
\hline & \multirow{3}{*}{$\begin{array}{c}\hat{F}_{t}(\$) \\
\text { (Max negative Balance) }\end{array}$} & Minimum & 40753.94 & 35999 & 32989.38 & 31846.97 \\
\hline & & Maximum & 58894 & 58137 & 58372.4 & 57329.97 \\
\hline & & Mean & 50004.15 & 47958.5 & 46128.7 & 44581.67 \\
\hline & \multirow{3}{*}{$\begin{array}{c}\text { D } \\
\text { (Final Project Duration) }\end{array}$} & Minimum & 40 days & 42 days & 47 days & 49 days \\
\hline & & Maximum & 40 days & 45 days & 50 days & 55 days \\
\hline & & Mean & 40 days & 44 days & 49 days & 54 days \\
\hline & \multirow{3}{*}{$\begin{array}{c}\hat{\mathrm{N}}_{t}(\$) \\
\text { (Net Project Profit) }\end{array}$} & Minimum & 19898 & 20113.6 & 22573.27 & 22742.51 \\
\hline & & Maximum & 27430 & 26260.6 & 24054.43 & 23830.9 \\
\hline & & Mean & 23224.6 & 23239.22 & 23238.2 & 23245.6 \\
\hline
\end{tabular}

\section{Activities of the Highest Impact}

Sensitivity analysis was carried out to determine the impact of the activities' start times on cash flow parameters. The results were analyzed based on extension increments of 5, 10, and 15 days for the three scenarios. The results of the sensitivity analysis are displayed as "Tornado" charts, the activities with the highest regression and correlation coefficient values are those with the highest impact on the output parameters. The positive value of the regression coefficient indicates a directly proportional relationship between an activity and an output. With sensitivity analysis, rank correlation coefficients are calculated between each input and output while the simulation is running. A correlation coefficient provides a meaningful measure of the degree to which the input and output change together.

As illustrated in Table 6 and Table 7, the impact of the activities on the cash flow parameters are presented by the regression coefficient of each activity. The high value of the regression coefficient of an activity in relation to an output indicates the degree of impact that activity has on this output. The positive value of the regression coefficient indicates a directly proportional relationship between the activity and the output. Table 6 and Table 7 present the results of the three extension increments in scenarios I and II, respectively. Table 6 presents the regression coefficients of all the activities in scenario I with an extension increment of five days, activity $\mathrm{B}$ has the highest regression coefficients to the financing cost and to the project profit. The regression coefficient values of activity $B$ to the financing cost and project profit are 0.059 and 0.059 , respectively. Activities B and A have the highest regression coefficient value to the maximum negative cumulative balance. The regression coefficient values of activities B and A are -0.407 and -0.38 . Activity G has the highest regression coefficient value to the project duration. The regression coefficient value of activity $\mathrm{G}$ is 0.133 .

In scenario I and with an extension increment of 10 days, activities $\mathrm{B}$ and $\mathrm{O}$ have the highest regression coefficients to the financing cost. The regression coefficient values of activities B and 0 are -0.097 and 0.1 , respectively. Activity B has the highest regression coefficient value to the project profit and the maximum negative cumulative balance. The regression coefficient values of activity $\mathrm{B}$ to the project profit and to the maximum negative cumulative balance are 0.097 and -0.437 , respectively. Activities $\mathrm{O}, \mathrm{L}$ and $\mathrm{F}$ have the highest regression coefficient value to the project duration. The regression coefficient value of activities $\mathrm{O}, \mathrm{L}$ and $\mathrm{F}$ are $0.132,0.116$ and 0.111 , respectively.

\section{Activities' Criticality}

Table 8 presents the top three activities that have the most impact on the total project duration, financing cost, the net project profit and the maximum negative cumulative balance for the two scenarios I and II with the three extension increments of 5, 10 and 15 days. The activities are ranked according to the correlation and regression coefficient values. These values measure the strength of the relationship between the activities' start times and the cash flow parameters.

\section{Scenario I}

As presented in Table 8, According to scenario I, activities B, $\mathrm{C}$ and $\mathrm{O}$ are the activities that are critical to the financing cost. Activities B, C and A are the critical activities for the maximum negative cumulative balance. Activity $\mathrm{O}$ is the critical activity for the project duration, and activities B, C and A are the critical activities for the project profit.

\section{Scenario II}

As presented in Table 8, Scenario II also shows that activities B and $\mathrm{O}$ are critical activities for the financing cost. Activities $\mathrm{A}$ and $\mathrm{C}$ are the critical activities for the maximum negative cumulative balance. Activities $\mathrm{C}$ and $\mathrm{M}$ are the critical activities to the project duration. Activity B is the critical activity to the project profit. Moreover, we can observe from the two scenarios that activities 
Table 6: The regression coefficients of the activities in scenario I

\begin{tabular}{|c|c|c|c|c|c|c|c|c|c|c|c|c|}
\hline Scenario & \multicolumn{12}{|c|}{ Scenario I } \\
\hline Extension & \multicolumn{4}{|c|}{5 days } & \multicolumn{3}{|c|}{10 days } & & \multicolumn{4}{|c|}{15 days } \\
\hline $\begin{array}{l}\text { Cash Flow } \\
\text { parameters }\end{array}$ & \multirow{2}{*}{$\hat{I}_{t}$} & \multirow{2}{*}{$\hat{F}_{t}$} & \multirow{2}{*}{$\hat{N}_{t}$} & \multirow[t]{2}{*}{ D } & \multirow{2}{*}{$\hat{I}_{t}$} & \multirow{2}{*}{$\hat{F}_{t}$} & \multirow{2}{*}{$\hat{N}_{t}$} & \multirow[t]{2}{*}{ D } & \multirow{2}{*}{$\hat{I}_{t}$} & \multirow{2}{*}{$\hat{F}_{t}$} & \multirow{2}{*}{$\hat{N}_{t}$} & \multirow[t]{2}{*}{ D } \\
\hline Activities & & & & & & & & & & & & \\
\hline A & 0.023 & -0.38 & -0.023 & 0.099 & -0.034 & -0.238 & 0.034 & 0 & 0.044 & -0.24 & -0.044 & 0.121 \\
\hline B & 0.059 & -0.407 & -0.059 & 0 & -0.097 & -0.437 & 0.097 & 0.101 & 0.118 & -0.398 & -0.118 & 0.156 \\
\hline C & 0.022 & -0.155 & -0.022 & 0 & -0.041 & -0.239 & 0.041 & 0.085 & 0.054 & -0.208 & -0.054 & 0.138 \\
\hline D & - & -0.06 & - & 0 & - & -0.11 & - & 0 & - & -0.103 & - & 0 \\
\hline $\mathbf{E}$ & - & - & - & 0.106 & - & 0.079 & - & 0.086 & 0.021 & 0.089 & -0.021 & 0.088 \\
\hline $\mathbf{F}$ & - & - & - & 0.093 & - & -0.108 & - & 0.111 & 0.022 & -0.16 & -0.022 & 0.147 \\
\hline $\mathbf{H}$ & - & 0.216 & - & 0.128 & - & 0.14 & - & 0 & - & 0.097 & - & 0.089 \\
\hline I & - & 0.126 & - & 0 & - & - & - & 0.108 & - & - & - & 0.106 \\
\hline $\mathbf{J}$ & - & - & - & 0 & - & - & - & 0.085 & - & - & - & 0.195 \\
\hline $\mathbf{K}$ & - & 0.171 & - & 0.116 & - & 0.169 & - & 0.103 & - & 0.157 & - & 0.149 \\
\hline $\mathbf{L}$ & - & - & - & 0.078 & - & - & - & 0.116 & - & - & - & 0.087 \\
\hline $\mathbf{M}$ & - & - & - & 0.14 & - & - & - & 0.104 & - & - & - & 0.096 \\
\hline $\mathbf{N}$ & - & 0.159 & - & - & - & 0.116 & - & - & -0.029 & 0.143 & 0.029 & 0.077 \\
\hline 0 & - & - & - & 0.081 & 0.1 & -0.063 & - & 0.132 & 0.12 & - & - & 0.185 \\
\hline
\end{tabular}

Table 7: The regression coefficients of the activities in scenario II

\begin{tabular}{|c|c|c|c|c|c|c|c|c|c|c|c|c|}
\hline \multirow{4}{*}{$\begin{array}{c}\text { Scenario } \\
\text { Extension } \\
\text { Cash Flow } \\
\text { parameters } \\
\text { Activities } \\
\end{array}$} & \multicolumn{12}{|c|}{ Scenario II } \\
\hline & \multicolumn{4}{|c|}{5 days } & \multicolumn{4}{|c|}{10 days } & \multicolumn{4}{|c|}{15 days } \\
\hline & \multirow{2}{*}{$\hat{I}_{t}$} & \multirow{2}{*}{$\hat{F}_{t}$} & \multirow{2}{*}{$\hat{N}_{t}$} & \multirow[t]{2}{*}{ D } & \multirow{2}{*}{$\hat{I}_{t}$} & \multirow[b]{2}{*}{$\hat{F}_{t}$} & \multirow{2}{*}{$\hat{N}_{t}$} & \multirow[t]{2}{*}{ D } & \multirow{2}{*}{$\hat{I}_{t}$} & \multirow{2}{*}{$\hat{F}_{t}$} & \multirow{2}{*}{$\hat{N}_{t}$} & \multirow[t]{2}{*}{ D } \\
\hline & & & & & & & & & & & & \\
\hline $\mathbf{A}$ & - & -0.26 & - & 0 & - & - & - & 0.158 & 0.029 & -0.182 & -0.029 & 0.081 \\
\hline B & -0.03 & -0.247 & 0.03 & 0 & -0.117 & - & 0.117 & 0.1 & 0.076 & -0.373 & -0.076 & 0.113 \\
\hline C & - & -0.184 & - & 0.124 & - & - & - & 0.155 & - & -0.254 & - & 0.138 \\
\hline D & - & -0.163 & - & 0 & - & - & - & 0.103 & - & -0.098 & - & 0.126 \\
\hline $\mathbf{E}$ & - & - & - & 0 & - & - & - & 0.119 & - & - & - & 0.09 \\
\hline $\mathbf{F}$ & - & - & - & 0 & - & - & - & 0 & - & -0.211 & - & 0.08 \\
\hline $\mathbf{H}$ & - & - & - & 0 & - & - & - & 0.148 & - & 0.155 & - & 0.087 \\
\hline I & - & - & - & 0.088 & - & - & - & 0 & - & - & - & 0.146 \\
\hline $\mathbf{J}$ & - & - & - & 0.1 & - & - & - & 0.151 & - & - & - & 0.105 \\
\hline $\mathbf{K}$ & - & 0.235 & - & 0 & - & - & - & - & - & 0.188 & - & - \\
\hline $\mathbf{L}$ & - & - & - & - & - & - & - & 0.124 & - & - & - & 0.202 \\
\hline M & - & - & - & 0.108 & - & - & - & 0.077 & - & - & - & 0.138 \\
\hline $\mathbf{N}$ & - & 0.142 & - & 0.091 & - & - & - & 0.089 & - & 0.185 & - & 0.112 \\
\hline $\mathbf{0}$ & - & - & - & 0.111 & 0.1 & - & - & 0.091 & 0.09 & - & - & 0.132 \\
\hline
\end{tabular}




\begin{tabular}{|c|c|c|c|c|c|c|}
\hline \multirow{2}{*}{ Scenarios } & \multirow{2}{*}{ Financial Parameters } & \multicolumn{4}{|c|}{ Extension Increment } & \multirow{2}{*}{$\begin{array}{l}\text { Critical } \\
\text { Activities }\end{array}$} \\
\hline & & Rank & 5days & 10 days & 15 days & \\
\hline \multirow{12}{*}{ Scenario I } & \multirow{3}{*}{$\begin{array}{c}\hat{I}_{t} \\
\text { (Financing cost) }\end{array}$} & Rank1 & Activity B & Activity & Activity 0 & 0 \\
\hline & & Rank2 & Activity A & Activity B & Activity B & B \\
\hline & & Rank3 & Activity C & Activity C & Activity C & $\mathrm{C}$ \\
\hline & \multirow{3}{*}{$\begin{array}{c}\hat{F}_{t} \\
\text { (Max negative Balance) }\end{array}$} & Rank1 & Activity B & Activity B & Activity B & B \\
\hline & & Rank2 & Activity A & Activity C & Activity A & A \\
\hline & & Rank3 & Activity $\mathrm{H}$ & Activity A & Activity C & $\mathrm{C}$ \\
\hline & \multirow{3}{*}{$\begin{array}{c}\text { D } \\
\text { Final Project Duration) }\end{array}$} & Rank1 & Activity M & Activity 0 & Activity J & 0 \\
\hline & & Rank2 & Activity G & Activity L & Activity 0 & - \\
\hline & & Rank3 & Activity H & Activity F & Activity B & - \\
\hline & \multirow{3}{*}{$\begin{array}{c}\hat{N}_{t} \\
\text { ( Net Project Profit) }\end{array}$} & Rank1 & Activity B & Activity B & Activity B & B \\
\hline & & Rank2 & Activity A & Activity C & Activity C & $\mathrm{C}$ \\
\hline & & Rank3 & Activity C & Activity A & Activity A & A \\
\hline \multirow{11}{*}{ Scenario II } & \multirow{3}{*}{$\begin{array}{c}\hat{I}_{t} \\
\text { (Financing cost) }\end{array}$} & Rank1 & Activity B & Activity B & Activity 0 & B \\
\hline & & Rank 2 & - & Activity 0 & Activity B & 0 \\
\hline & & Rank3 & - & - & Activity A & - \\
\hline & \multirow{3}{*}{$\begin{array}{c}\hat{F}_{t} \\
\text { (Max negative Balance) }\end{array}$} & Rank 1 & Activity A & - & Activity B & B \\
\hline & & Rank 2 & Activity B & - & Activity C & - \\
\hline & & Rank 3 & Activity K & - & Activity F & - \\
\hline & \multirow{3}{*}{$\begin{array}{c}\text { D } \\
\text { (Final Project Duration) }\end{array}$} & Rank 1 & Activity C & Activity A & Activity I & - \\
\hline & & Rank 2 & Activity 0 & Activity C & Activity C & $\mathrm{C}$ \\
\hline & & Rank 3 & Activity M & Activity G & Activity M & M \\
\hline & \multirow{2}{*}{$\begin{array}{c}\hat{N}_{t} \\
\text { (Net Project Profit) }\end{array}$} & Rank 1 & Activity B & Activity B & Activity B & B \\
\hline & & Rank 2 & - & - & Activity A & - \\
\hline
\end{tabular}

$\mathrm{B}$ and $\mathrm{O}$ are the highest impact activities on the financing cost. Activity $\mathrm{C}$ is presented as the highest impact activity to the financing cost for scenario I. Activity A is presented as the highest impact activity to the maximum negative cumulative balance for scenarios I and II. Activity C is presented as the highest impact activity to the maximum negative cumulative balance for scenarios I and II. Activity $\mathrm{O}$ appears to be the highest impact activity for the project duration for scenario I. Activities C and M are presented as the highest impact activities to the project duration in scenario II. Activities $\mathrm{C}$ and $\mathrm{A}$ are presented as the highest impact activities to the project profit in scenario I. Activity B appears as one of the highest impact activity to the project profit for, scenario I and scenario II.

According to the results of Scenarios I and II in this case study, we can determine the criticality of the activities, or those activities that have the highest regression and correlation coefficients and consequently have the highest impact on the cash flow parameters. It was observed that these same activities were repeatedly the highest impact activities for the scenarios I and II. As discussed above, activities' criticality to cash-flow parameters, which is an indication of the number of times a given activity determined a particular cash-flow parameter over the number of runs, can be assessed in detail. The critical activities to the financing cost are activities $\mathbf{B}, \mathbf{C}$ and $\mathbf{0}$. The critical activities to the maximum negative cumulative balance are activities $\mathbf{B}, \mathbf{A}$ and C. The critical activities to project duration are activities G, J, C, $\mathbf{0}$, and $\mathbf{M}$, and the critical activities to project profit are activities $\mathrm{B}, \mathrm{C}$ and $\mathrm{A}$.

\section{Advanced Sensitivity Analysis}

In this section a detailed analysis is conducted on the critical activities to cash flow parameters, as identified in the previous section. The values of the critical activities' start times are changed in specific ranges where the effect of these changes to the cash flow parameters are evaluated and measured. In this step, we will measure the criticality of these activities to cash flow parameters. Studying the impact of changing activities' start times in a specific range on the outputs will lead to an assessing the activities' criticality to cash flow parameters. The analysis in this section is done for scenario II with an extension of 5 days. 


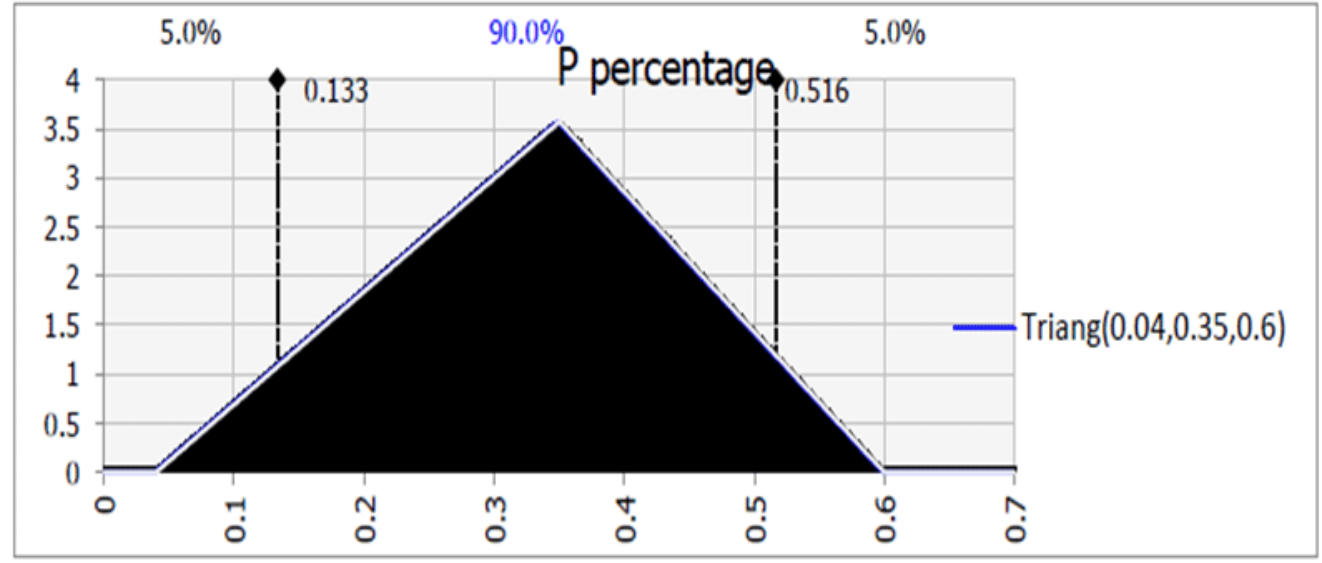

Figure 3: Triangle distribution of p percentage

\section{Activities`Criticality to the Financing Cost}

The start times of activities $\mathrm{B}, \mathrm{C}$ and $\mathrm{O}$ are varied by decrementing and incrementing their values from the respective mean value across the range from $-30 \%$ to $+30 \%$. The change of the start times' values of activities $\mathrm{B}, \mathrm{C}$ and $\mathrm{O}$ changes the mean values of the financing cost from $\$ 430.3$ to $\$ 434.67$, from $\$ 430$ to $\$ 432.5$, and from $\$ 432.3$ to $\$ 420$, respectively. The result shows that activity $\mathrm{O}$ is the activity that is most critical to the financing cost, as shown in Figure 4a.

\section{Activities' Criticality to the Maximum Negative Cumulative Balance}

The analysis focuses on the inputs, which are the start times of activities A, B and C that are critical to the maximum negative cumulative balance. As shown in Figure $4 \mathrm{~b}$, the start times of activities A, B and C vary by incrementing and decrementing their values from their respective mean values across the range from $+30 \%$ to $-30 \%$. Changing the start time values changes the mean values of the maximum negative cumulative balance from $\$ 48,681.7$ to $\$ 47,459$, from $\$ 48,664.3$ to $\$ 47,232.5$ and from $\$ 48,435.6$ to $\$ 47,459.8$, for activities A, B and C, respectively. The results show that activities $A, B$ and $C$ are the critical activities to the maximum negative cumulative balance.

\section{Activities' Criticality to the Project Total Duration}

The start times of activities $\mathrm{G}, \mathrm{J}, \mathrm{C}, \mathrm{O}$, and $\mathrm{M}$ are varied by decrementing and incrementing their values from their respective mean values across the range from $-30 \%$ to $+30 \%$. Changing the start times of activities $\mathrm{G}, \mathrm{J}, \mathrm{O}$, and $\mathrm{M}$ changes the mean values of the total project duration from 42 to 45 days, from 43 to 49 days, from 45 to 53 days and from 43 to 51 days, respectively, as shown in Figure 4c. The results show that activities $\mathrm{O}$ and $\mathrm{M}$ are the ones most critical to the project duration.

\section{Activities' Criticality to the Project Profit}

The start times of activities A, B and C are varied by decrementing and incrementing their values from the respective mean value across the range from $-30 \%$ to $+30 \%$. Changing the start times of activities A, B and C changes the mean values of the project profit from $\$ 23,228.9$ to $\$ 23,227.4$, from $\$ 23,230$ to $\$ 23,227.8$, and from $\$ 23,229.5$ to $\$ 23,227.8$, respectively. As shown in Figure 4d, activity B is the activity which is most critical to the project profit. 


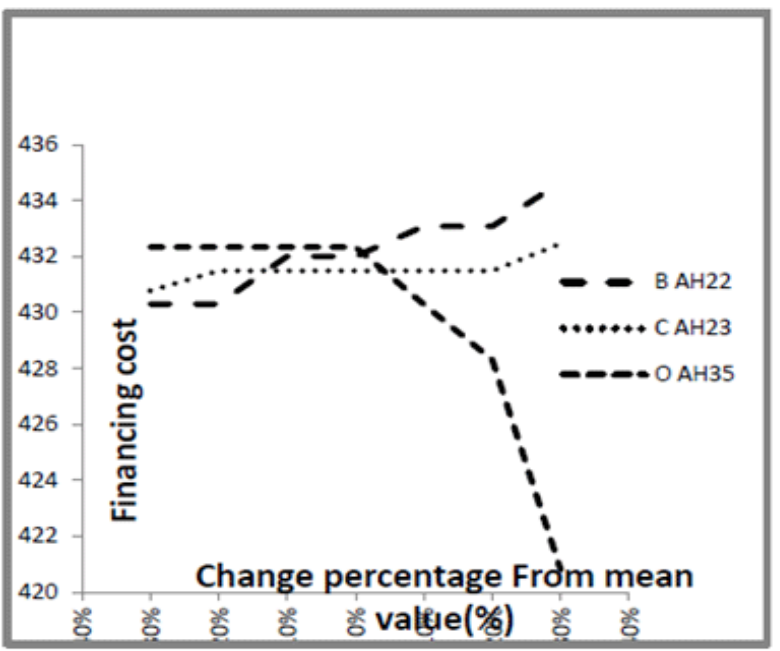

a: The financing cost versus the change of activities B, C and O's start times

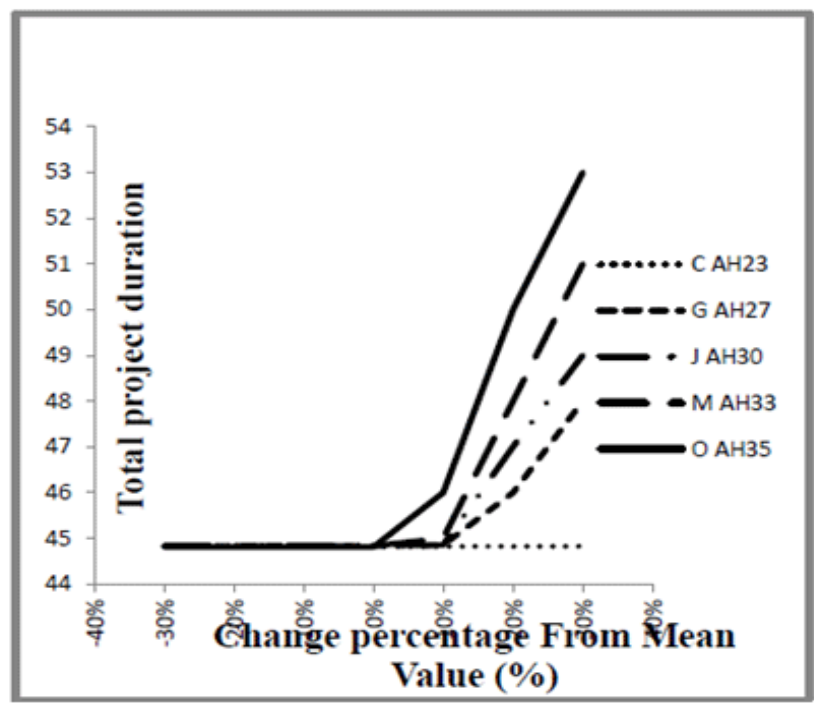

c: The total project duration versus the change start times

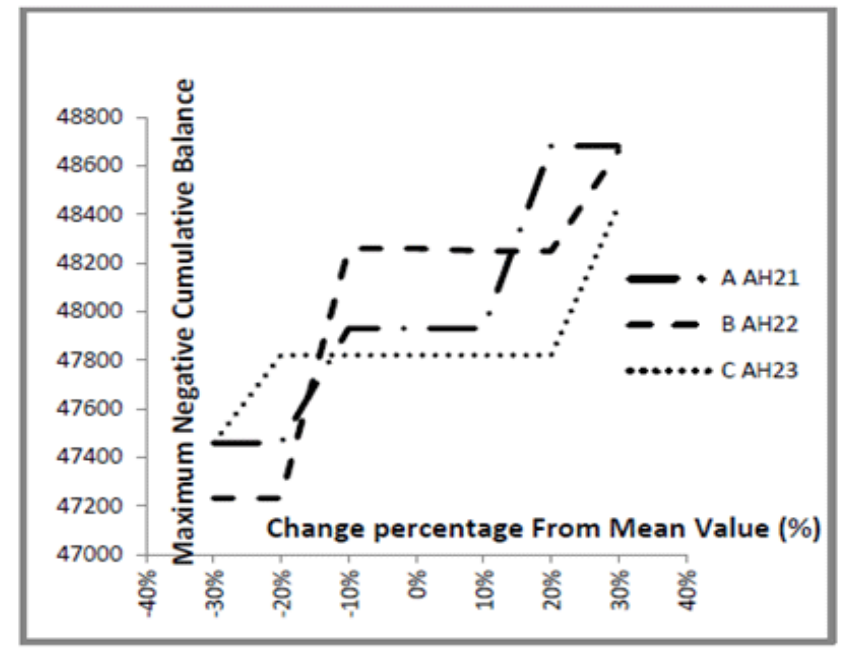

b: The maximum negative cumulative balance versus the change of activities A, B and C start times

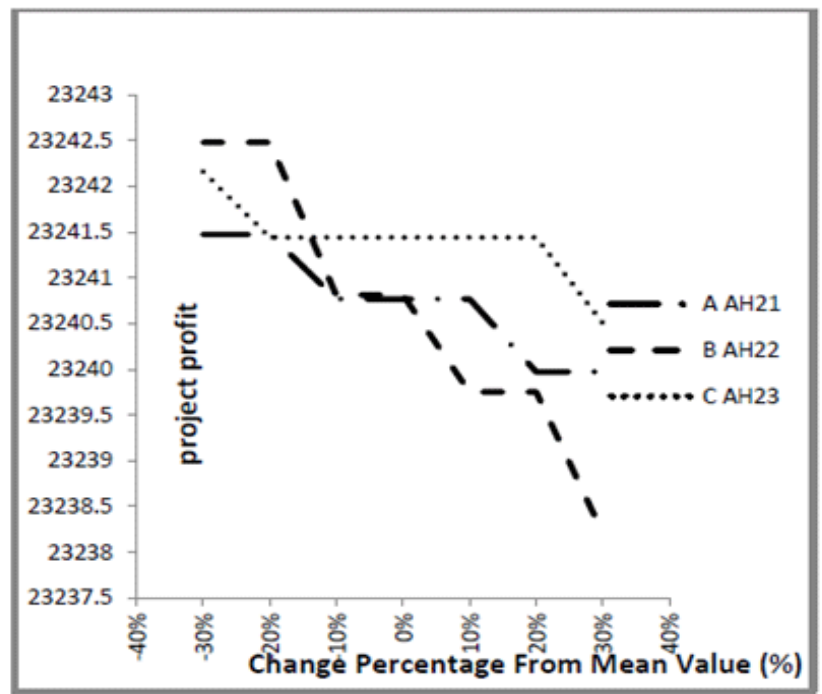

d: The project profit versus change of activities' of activities' start times

Figure 4: The Impact of changing activities' start times on cash flow parameters

\section{Conclusion}

A careful evaluation of the interaction between the project cash flow and the project schedule was carried out. The Monte Carlo Simulation was used to generate stochastic schedules. The @RISK commercial simulation software was used to implement the simulation while considering the stochastic nature of the cash inflow and cash outflow. Three scenarios were defined, based on the number of qualitative factors that impact the project cash inflow and cash outflow transactions that they incorporate.
Moreover, three extension increments of 5, 10, and 15 days were used for each scenario. Overall, cash outflow qualitative factors increase cash outflow transactions by approximately $10.6 \%$, while cash inflow transactions decrease cash inflow transaction by $9 \%$.

The results indicate that the mean value of the financing cost and the maximum negative cumulative balance decrease with the increase of the time extension. Moreover, their values increase from scenario I to scenario III due to the incorporated qualitative factors, which consequently increase the cash outflow 
and decrease the cash inflow transactions. Since the financing cost decreases with the increase of the extension increment, the profit also increases with the increase of the extension increment. According to the results, the schedule generated with a 10-day extension in Case Scenario I is considered to be the best schedule. This generated schedule indicates total project duration 45 days, a maximum project profit of $\$ 24,571.32$, a maximum negative cumulative balance of $\$ 55,991.18$ and a maximum financing cost of $\$ 544.8$. The terminology of activities' criticality was introduced to describe the sensitivity of the individual cashflow parameters to the delays in the activities' start times. The criticality of activities is an indication of the number of times an activity determines the outputs over the number of the simulation runs. Assessing activities' criticality helps managers focus on and prioritize the activities that should be completed on time. Consequently, allows practitioners assess potential risk associated with the project finance needs. The study considered cost plus fee contract. It is recommended in future work to develop the methodology to include different type of contracts. In this research, the durations of activities are deterministic. However, future work could consider the uncertainty in the duration of activities, which would make the alternative generated schedules more accurate. Moreover, this would help in studying the impact of activity durations on the project cash flow. In addition, it could be a very useful way to measure the activities' criticality.

\section{References}

1. Ahmed MH. Assessment of Activities Criticality Related to Cash Flow Parameter. Master dissertation, Department of Building, Civil and Environmental Engineering, Concordia University. 2012.

2. Al-Issa A, Zayed T. Factors Affect Project Cash Flow. Construction Research Congress (CRC), ASCE, Grand Bahamas Island. 2007.

3. Chen CW, Wang MH-L, Liu KF-R, Chen TH. Application of Project Cash Management and Control for Infrastructure. Journal of Marine Science and Technology. 2010;18(5):644-651.

4. Chen H-L, OBrien WJ, Herbsman ZJ. Assessing the Accuracy of Cash Flow Models: The Significance of Payment Conditions. ASCE-Journal of Construction Engineering and Management. 2005;131(6):669676.

5. Elazouni A. Heuristic Method for Multi-project finance-based scheduling. ASCE-Journal of Construction Management and Economics. 2009;27(2):199-211.

6. Elazouni A, Gab-Allah AA. Finance-Based Scheduling of Construction Projects Using Integer Programming. ASCE-Journal of Construction Engineering and Management. 2004;130(1):15-24.

7. Waligora G. Discrete continuous project scheduling with discounted cash flows - A tabu search approach. Computers and Operations Research. 2008;35(7):2141-2153.

8. Hwee NG, Tiong RLK. Model on cash flow forecasting and risk analysis for contracting firms. International Journal of Project Management. 2002;20(5):351-363.

9. Javid M, Seneviratne PN. Investment Risk Analysis in Airport Parking Facility Development. ASCE- Construction Engineering and Management. 2000;126(4):298-305.
10. Kaka A, Lewis J. Development of a company-level dynamic cash flow forecasting model (DYCAFF). ASCE-Construction Management and Economics. 2003;21(7):693-705

11.Kimms A. Maximizing the Net Present Value of a Project Under Resource Constraints Using a Lagrangian Relaxation Based Heuristic with Tight Upper Bounds. Annals of Operations Research. 2001;102(1-4):221-236.

12. Liu Y, Zayed T, Li S. Cash Flow Analysis of Construction Projects. Canadian Society of Civil Engineering (CSCE) Conference, St. John's, Newfoundland, Canada, ICS-201.2009.

13. Najafi AA, Azimi F. A Priority Rule-Based Heuristic for Resource Investment Project Scheduling Problem with Discounted Cash Flows and Tardiness Penalties. Mathematical Problems in Engineering. 2009;2009:1-10.

14. Navon R. Company-Level Cash-Flow Management. ASCE- Journal: Construction Engineering and Management. 1996;122(1):22-29.

15. Olveczky PC, Caccamo M. Formal simulation and analysis of the CASH scheduling algorithm in Real-Time Maude. Fundamental Approaches to Software Engineering (FASE'06). Lecture Notes in Computer Science. 2006;3922:357-372.

16.Padman R, Zhu D. Knowledge integration using problem spaces: A study in resource-constrained project scheduling. J Scheduling. 2006;9(2):133-152.

17. Park HK, Han SH, Russell JS. Cash Flow Forecasting Model for General Contractors Using Moving Weights of Cost Categories. ASCE-Construction Engineering and Management, 2005;21(4):164172 .

18.Russell RA. A Comparison of Heuristics for Scheduling Projects with Cash Flows and Resource Restrictions. Management Science. 1986;32(10):1291-1300

19. Vanhoucke M, Demeulemeester E, Herroelen W. On Maximizing the Net Present Value of a Project under Renewable Resource Constraints. Management Science. 2001;47(8):1113-1121.

20.Zayed T, Liu Y. Cash flow modeling for construction projects. Engineering, Construction and Architectural Management. 2014;21(2):170-189.

21.Zhu D, Padman R. A Metaheuristic Scheduling Procedure for Resource-Constrained Projects with Cash Flows. Naval Research Logistics (NRL). 1999;46(8):912-927.

22. Chen PH, Weng H. A two-phase GA model for resource-constrained project scheduling. Automation in Construction. 2009:18(4) 485-498.

23.El-Abbasy MS, Elazouni A, Zayed T. Generic scheduling optimization model for multiple construction projects. Journal of Computing in Civil Engineering. 2017;31(4):04017003.

24.Alavipour SR, Arditi D. Optimizing Financing Cost in Construction Projects with Fixed Project Duration. Journal of Construction Engineering and Management. 2018;144(4):04018012.

25. Han SH, Park HK, Yeom SM, Myung Jin Chae MJ, Kim DY. Riskintegrated cash flow forecasting for overseas construction projects. KSCE Journal of Civil Engineering. 2014;18(4):875-886.

26.Lu Q, Won J, Cheng CP. A financial decision making framework for construction projects based on 5D Building Information Modeling (BIM). International Journal of Project Management. 2016;34(1):3-21. 